\title{
Effects of the Noradrenergic System in Rat White Matter Exposed to Oxygen-Glucose Deprivation In Vitro
}

\author{
Maria A. Nikolaeva, ${ }^{1}$ Sandra Richard, ${ }^{1}$ Abdeslam Mouihate, ${ }^{2}$ and Peter K. Stys ${ }^{2}$ \\ ${ }^{1}$ Division of Neuroscience, Ottawa Health Research Institute, University of Ottawa, Ottawa, Ontario, Canada K1Y 4E9, and ${ }^{2}$ Department of Clinical \\ Neurosciences, Hotchkiss Brain Institute, University of Calgary, Calgary, Alberta, Canada T2N 4N1
}

\begin{abstract}
Norepinephrine (NE) is released in excess into the extracellular space during oxygen-glucose deprivation (OGD) in brain, increasing neuronal metabolism and aggravating glutamate excitoxicity. We used isolated rat optic nerve and spinal cord dorsal columns to determine whether the noradrenergic system influences axonal damage in white matter. Tissue was studied electrophysiologically by recording the compound action potential (CAP) before and after exposure to $60 \mathrm{~min}$ of OGD at $36^{\circ} \mathrm{C}$. Depleting catecholamine stores with reserpine was protective and improved CAP recovery after $1 \mathrm{~h}$ of reperfusion from $17 \%$ (control) to $35 \%$. Adding NE during OGD decreased CAP recovery to $8 \%$, and adding NE to reserpine during OGD eliminated the protective effect of the latter. Selective inhibitors of $\mathrm{Na}^{+}$-dependent norepinephrine transport desipramine and nisoxetine improved recovery to $58 \%$ and $44 \%$, respectively. $\alpha 2$ adrenergic receptor agonists UK14,304 and medetomidine improved CAP recovery to $41 \%$ and $46 \%$ after $1 \mathrm{~h}$ of OGD. Curiously, $\alpha 2$ antagonists alone were also highly protective (e.g., atipamezole: $86 \%$ CAP recovery), at concentrations that did not affect baseline excitability. The protective effect of $\alpha 2$ receptor modulation was corroborated by imaging fluorescent $\mathrm{Ca}^{2+}$ and $\mathrm{Na}^{+}$indicators within axons during OGD. Both agonists and antagonists significantly reduced axonal $\mathrm{Ca}^{2+}$ and $\mathrm{Na}^{+}$accumulation in injured axons. These data suggest that the noradrenergic system plays an active role in the pathophysiology of axonal ischemia and that $\alpha 2$ receptor modulation may be useful against white matter injury.
\end{abstract}

Key words: axon; ischemia; sodium; calcium; norepinephrine; confocal microscopy

\section{Introduction}

Norepinephrine (NE) is released in excess into the extracellular space during oxygen-glucose deprivation (OGD) (Globus et al., 1989; Bhardwaj et al., 1990; Perego et al., 1992) in the brain, increasing neuronal metabolism and aggravating glutamate excitotoxicity (Bickler and Hansen, 1996; Talke and Bickler, 1996). However, no data are available regarding the effect of ischemia on the release of NE and its influence on white matter. The primary regulators of $\mathrm{NE}$ release are $\alpha 2$-adrenergic autoreceptors $(\alpha 2 \mathrm{ARs})$. These are catecholamine receptors, which are sensitive to the neuron's own transmitter and function as releaseinhibiting autoreceptors on noradrenergic neurons. Activation of these receptors by NE inhibits further release of NE during nerve stimulation, while blocking them enhances the stimulation-evoked release of the neurotransmitter (Langer, 1974; Dixon et al., 1979); therefore, they have been classified as autoinhibitory receptors.

In models of cerebral ischemia and excitotoxicity, both $\alpha 2 \mathrm{AR}$

\footnotetext{
Received Dec. 1, 2008; revised Jan. 4, 2009; accepted Jan. 5, 2009.

This work was supported in part by Canadian Institutes of Health Research and the Multiple Sclerosis Society of Canada (operating), and the Heart and Stroke Foundation of Ontario Center for Stroke Recovery (equipment). P.K.S. was supported by the Heart and Stroke Foundation of Ontario Career Investigator and the Alberta Heritage Foundation for Medical Research Scientist Awards.

Correspondence should be addressed to Peter K. Stys, Department of Clinical Neurosciences, Hotchkiss Brain Institute, University of Calgary, HRIC 1AA22, 3330 Hospital Drive North West, Calgary, Alberta, Canada T2N 4N1. E-mail: pstys@ucalgary.ca.

DOI:10.1523/JNEUROSCI.5729-08.2009

Copyright $\odot 2009$ Society for Neuroscience $\quad$ 0270-6474/09/291796-09\$15.00/0
}

agonists and antagonists have been shown to be neuroprotective in in vivo and in vitro studies (Martel et al., 1998; Puurunen et al., 2001; Ma et al., 2005). The mechanisms of $\alpha 2 \mathrm{AR}$-mediated protection remain elusive, although different possible biochemical and physiological cascades at nerve terminals were suggested, such as inhibition of the intracellular $\mathrm{Ca}^{2+}$ rise, activation of outward rectifying $\mathrm{K}^{+}$channels, modulation of the release of other transmitters at different nerve terminals, and enhancement of glutamate scavenging by astrocytes (Ma et al., 2005).

While in gray matter areas, $\alpha 2 \mathrm{AR}$ were found in the perikaryon and in association with the neuropil (Talley et al., 1996; Milner et al., 1998), in mature white matter $\alpha 2$ ARs were suggested to be present on glia and/or microvessels, with no evidence of adrenergic receptors on axons of descending or ascending white matter tracts (Venugopalan et al., 2006). The role of $\alpha 2$ ARs in mature white matter during metabolic inhibition has not been investigated, although several reports indicate potent neuroprotective effects of $\alpha 2 \mathrm{AR}$ modulation in perinatal models of gray and white matter injury (Laudenbach et al., 2002; Paris et al., 2006). There is also evidence for $\beta$ adrenoceptor-mediated modulation of excitability of premyelinated optic nerve axons; however, this effect is lost as the tract matures and axons become fully myelinated (Honmou and Young, 1995).

Multiple reports about the neuroprotective effect of $\alpha 2 \mathrm{AR}$ agonists in a variety of models of cerebral metabolic stress prompted us to investigate whether manipulating $\alpha 2 \mathrm{AR}$ in adult white matter might offer neuroprotection during OGD. Using 
electrophysiology and confocal microscopy we demonstrate NEdependent axonal $\mathrm{Ca}^{2+}$ and $\mathrm{Na}^{+}$changes, modulated by $\alpha 2 \mathrm{AR}$ in injured rat white matter in vitro. We also demonstrate prominent $\alpha 2 \mathrm{AR}$ immunoreactivity associated with myelinated optic and dorsal column axons suggesting a direct effect of these receptors on central fibers. The robust protection afforded by $\alpha 2 \mathrm{AR}$ modulators, together with favorable clinical tolerability observed in other studies (Ma et al., 2005), suggests that these agents may represent an attractive class of molecules for the development of protective strategies for human white matter disorders.

\section{Materials and Methods}

Electrophysiology. For electrophysiological recordings, both optic nerves and spinal cord dorsal columns from adult Long-Evans male rats were used. For the optic nerve recordings, rats were anesthetized with $80 \%$ $\mathrm{CO}_{2} / 20 \% \mathrm{O}_{2}$, decapitated and nerves were dissected out. For dorsal columns experiments, rats were anesthetized with pentobarbital, perfused with $0 \mathrm{Ca}^{2+} / 0.1 \mathrm{~mm}$ EGTA CSF, thoracic spinal cord was removed, placed in cold oxygenated zero- $\mathrm{Ca}^{2+} / 0.1 \mathrm{~mm}$ EGTA CSF and dorsal column slices were dissected free. The tissue was then placed in an oxygenated chamber at $36^{\circ} \mathrm{C}$ for recording of propagated compound action potentials (CAPs) using suction electrodes. The tissue was aerated with a $95 \% \mathrm{O}_{2} / 5 \% \mathrm{CO}_{2}$ gas mixture, and perfused with artificial CSF (aCSF: 126 $\mathrm{NaCl}, 3.0 \mathrm{KCl}, 2 \mathrm{Mg}_{2} \mathrm{SO}_{4}, 26 \mathrm{NaHCO}_{3}, 1.25 \mathrm{NaH}_{2} \mathrm{PO}_{4}, 2.0 \mathrm{CaCl}_{2}, 10$ dextrose (in $\mathrm{mM}$ ), $\mathrm{pH}$ 7.4). Under control conditions, in vitro white matter CAP amplitudes and waveshapes remain very stable for $>3 \mathrm{~h}$ at $37^{\circ} \mathrm{C}$ (Stys et al., 1991; Li et al., 1999; Malek et al., 2003). OGD was induced by switching to a 0 glucose CSF (glucose replaced by equimolar sucrose) and $95 \% \mathrm{~N}_{2} / 5 \% \mathrm{CO}_{2}$ mixture for $1 \mathrm{~h}$, followed by $1 \mathrm{~h}$ of reperfusion/reoxygenation. Ratios of CAP area after reperfusion to pre-OGD/predrug control areas were used to quantitate the degree of functional recovery after OGD.

Confocal microscopy. Optic nerves were dissected out of the brain and placed in an interface perfusion chamber in $\mathrm{Ca}^{2+}$-free aCSF at $36^{\circ} \mathrm{C}$. One end of each nerve was inserted into a suction pipette filled with loading buffer (aCSF with $\mathrm{NaCl}$ replaced by $126 \mathrm{~mm}$ of $\mathrm{N}$-methyl-D-glucamine, with $\mathrm{CaCl}_{2}$ omitted, roughly mimicking intra-axonal ion concentrations) and fluorescent dyes: either Fluo- 4 dextran $\left(\mathrm{Ca}^{2+}\right.$ indicator $)$ or CoroNa Green $\left(\mathrm{Na}^{+}\right.$indicator), and the ion-insensitive Alexa Fluor 594 dextran for visualization of axonal profiles. After application of the suction pipette to the end of the nerve, perfusion was switched to a normal $\mathrm{Ca}^{2+}$-replete CSF and nerves were loaded for $1.5 \mathrm{~h}$, removed from the loading pipette and rinsed in normal CSF for a further $1.5 \mathrm{~h}$. Nerves were placed in a custom-built perfusion chamber, and mounted on an upright Nikon $\mathrm{C} 1$ confocal laser-scanning microscope. Imaging was performed at $36^{\circ} \mathrm{C}$ with a $60 \times$ water-immersion objective. Fluorescence changes were normalized to average basal levels and reported as a ratio of signal collected from ion-sensitive to ion-insensitive fluorophores plotted against time. Chemical "ischemia" was induced by using the mitochondrial inhibitor $\mathrm{NaN}_{3}(2 \mathrm{~mm}$ ) and zero-glucose (replaced with $10 \mathrm{~mm}$ sucrose) in the perfusate. All drugs were applied $30 \mathrm{~min}$ before the onset of OGD/chemical ischemia and continued throughout OGD.

Immunohistochemistry. Rat optic nerves (RONs) and spinal cord were dissected out, fixed in $2-4 \%$ paraformaldehyde for $1-3 \mathrm{~h}$ and then cryoprotected in $20 \%$ sucrose $0.1 \mathrm{M}$ phosphate buffer at $4^{\circ} \mathrm{C}$ overnight. Tissue was then cut at $25-35 \mu \mathrm{m}$, mounted on a slide and air-dried for $2 \mathrm{~h}$ or overnight. For norepinephrine transporter (NET) staining, an antigen retrieval procedure was required: slides were boiled in a sodium citrate solution for $20 \mathrm{~min}$. After cooling, the slides were incubated in ice-cold acetone for $30 \mathrm{~min}$. The slides were then rinsed 2-3 times for $10 \mathrm{~min}$ in $0.05 \mathrm{M}$ Tris buffer of with $1.5 \% \mathrm{NaCl}$ or PBS and $1 \%$ Triton X-100 (TBS-T or PBS-T), followed by $10 \%$ normal goat serum (NGS) in TBS-T for blocking for $1 \mathrm{~h}$ at room temperature and incubated overnight in primary antiserum diluted in TBS-T or PBS-T with $2 \%$ NGS at the following dilutions: 1:1000 for $\alpha 2$ AR (Sigma), 1:1000 for neurofilament 160 clone (Sigma), 1:1500 for $\mathrm{Na}^{+} / \mathrm{K}^{+}$ATPase $\alpha$-3 subunit (Affinity BioReagents), 1:200 for glial fibrillary acidic protein (GFAP; Boehringer Mannheim Biochemica), 1:200 for norepinephrine transporter (Santa Cruz

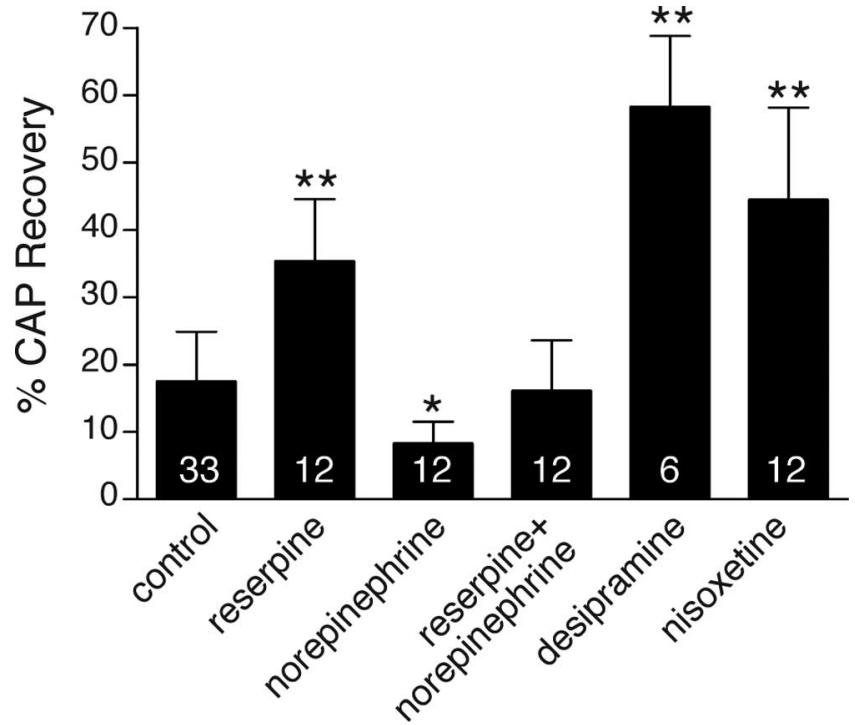

Figure 1. CAP-area recovery recorded from optic nerves injured by $1 \mathrm{~h}$ of $0 \mathrm{GD} / 1 \mathrm{~h}$ of reperfusion (control), in the presence of reserpine $(1 \mu \mathrm{M}), \mathrm{NE}(500 \mu \mathrm{M})$, reserpine plus NE, desipramine $(10 \mu \mathrm{M})$, nisoxetine $(5 \mu \mathrm{M})$, demonstrating the dependence of injury on the availability of norepinephrine in the extracellular space. Numbers within the bars represent the number of nerves used for each treatment. Error bars indicate SD. ${ }^{*} p=0.04{ }^{* *} p<10^{-7}$ versus control.

Biotechnology). After two or three 10 min rinses in TBS-T, samples were incubated in anti-mouse Texas red at 1:100 or anti-mouse Alexa 568 at 1:200 in combination with anti-rabbit Alexa-488 at 1:500 (Invitrogen). Tissue was then rinsed 2-3 times in TBS-T or PBS-T. Some sections were then incubated in anti-neurofilament antibody directly conjugated with Alexa Fluor 660 dye (Invitrogen) for $3 \mathrm{~h}$ at 1:75 dilution for triple labeling. Slides were coverslipped with Prolong Antifade Reagent (Invitrogen), and images were collected on a confocal microscope with a $60 \times$ oil-immersion objective.

Statistics. All data are expressed as means \pm SD. Statistical differences were calculated by ANOVA with Tukey's HSD (Honestly Significant Difference) test for multiple comparisons. Reported $n$ values represent numbers of individually analyzed axons (imaging) or numbers of nerves (electrophysiology).

\section{Results}

The effect of extracellular NE content on CAP-area recovery

To investigate whether there is any catecholamine effect on the ischemic pathogenesis in RONs, we depleted endogenous catecholamines using reserpine (Fig. 1). Reserpine is an irreversible inhibitor of the vesicular monoamine transporter and decreases tissue NE content by depleting its vesicular storage (Schuldiner et al., 1995). Reserpine (1 $\mu \mathrm{M})$ pretreatment improved CAP recovery after $1 \mathrm{~h}$ OGD plus $1 \mathrm{~h}$ of reperfusion from $17 \pm 7 \%$ (control) to $35 \pm 9 \%\left(p=8.8 \times 10^{-8} ; n=12\right)$. Adding NE $(500 \mu \mathrm{M})$ during OGD decreased CAP recovery to $8.2 \pm 3 \%(p=0.039$; $n=12)$, whereas adding NE to reserpine $(n=12)$ during OGD eliminated the protective effect of the latter $\left(p=4.2 \times 10^{-6}\right.$ reserpine plus NE vs reserpine), with CAPs recovering to $16 \pm$ $7 \%(p=0.99$ vs control OGD). NE alone caused an insignificant 9.9\% increase in mean CAP magnitude in control nerves before OGD ( $p=0.125$, Wilcoxon two-tail test), in agreement with previous studies showing no effect of this agent on mature optic nerve excitability (Honmou and Young, 1995).

Desipramine and nisoxetine are selective NET inhibitors. The uptake of NE into cells is performed by NET, a member of a large family of transporters that concentrate NE by cotransport with $\mathrm{Na}^{+}$and $\mathrm{Cl}^{-}$(Mandela and Ordway, 2006). During metabolic inhibition, a decrease of ATP levels followed by inhibition of 


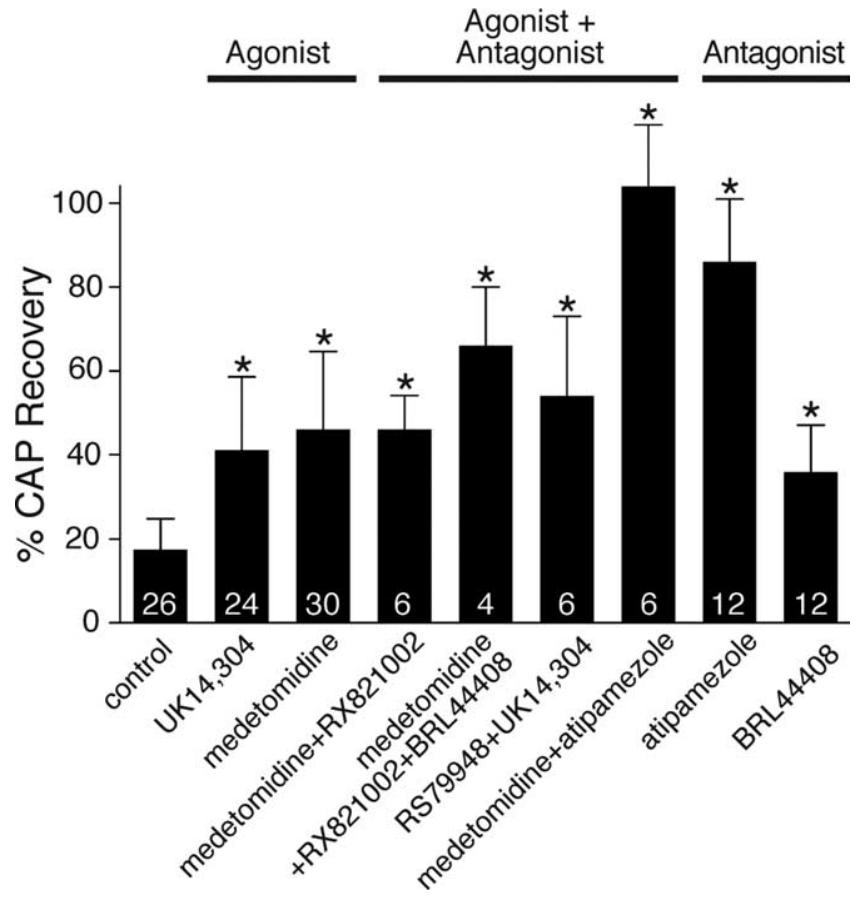

Figure 2. Optic nerve CAP-area recovery in the presence of $\alpha 2 A R$ agonists: UK14,304 (0.1 $\mu \mathrm{M})$ and medetomidine (10 $\mu \mathrm{m})$; agonists and antagonists: RX 821002 (1-10 $\mu \mathrm{M})$, BRL 4406 $(10 \mu \mathrm{M}), \mathrm{RS} 79948(0.1 \mu \mathrm{M})$ and atipamezole $(50 \mu \mathrm{M})$; antagonists alone: atipamezole and BRL 4406 , illustrating the strong dependence of $0 G D$-induced injury on $\alpha 2$ AR modulation. Numbers within the bars represent the number of nerves used for each treatment. Error bars indicate SD. ${ }^{*} p<0.009$ versus control.

$\mathrm{Na}^{+} / \mathrm{K}^{+}$ATPase activity leads to intracellular $\mathrm{Na}^{+}$accumulation and reversal of the NET, resulting in release of transmitter (Vizi, 2000). Given that extracellular NE appears deleterious (results above), and if the reverse operation of the $\mathrm{Na}^{+}$-dependent transporter leads to NE release during metabolic inhibition, then blocking the transporter during OGD should decrease release of endogenous NE, reduce extracellular NE concentration and improve outcome. The protective effects of desipramine $(10 \mu \mathrm{M})$ and nisoxetine $(5 \mu \mathrm{M})(58 \pm 11 \%, n=6$ and $44 \pm 14 \%, n=12$, respectively; $p=2 \times 10^{-11}$ for each group vs drug-free control OGD) are consistent with such a mechanism of NET-mediated NE release. Together, these experiments suggest that lower concentrations of NE in the extracellular space are associated with better functional recovery, and implicate the noradrenergic system in the ischemic response of white matter.

\section{Effects of $\alpha 2 \mathrm{AR}$ agonists and antagonists on CAP recovery}

The $\alpha 2$ AR agonists UK14,304 (5'-bromo-6-[2-imidazolin-2-ylamino]-quinoxaline; $0.1 \mu \mathrm{M})$ and medetomidine $(10 \mu \mathrm{M})$ improved CAP recovery after OGD to $41 \pm 17 \%$ and $46 \pm 19 \%$ versus $17 \%$ in control $\left(p=1.1 \times 10^{-6} ; n=24\right.$ and $p=5.6 \times$ $10^{-10} ; n=30$ ) (Fig. 2). Interestingly, preapplication of $\alpha 2$ antagonists [RX $821002(1-10 \mu \mathrm{M})$, BRL $4406(10 \mu \mathrm{M})$, RS $79948(0.1$ $\mu \mathrm{M})$ or atipamezole $(50 \mu \mathrm{M})]$ with the agonists did not decrease the effect of the agonists. On the contrary, it slightly increased their protective effect and in the case of the most specific antagonist, atipamezole (Virtanen et al., 1989), allowed CAP area to recover to $104 \pm 15 \%$ of control when combined with the agonist medetomidine. Application of $\alpha 2 \mathrm{AR}$ antagonists alone (BRL 4406 , atipamezole) was also highly protective, particularly with the latter agent $\left(86 \pm 15 \%, p=6.6 \times 10^{-14} ; n=12\right)$. To test whether this protective effect extends to other white matter tracts,

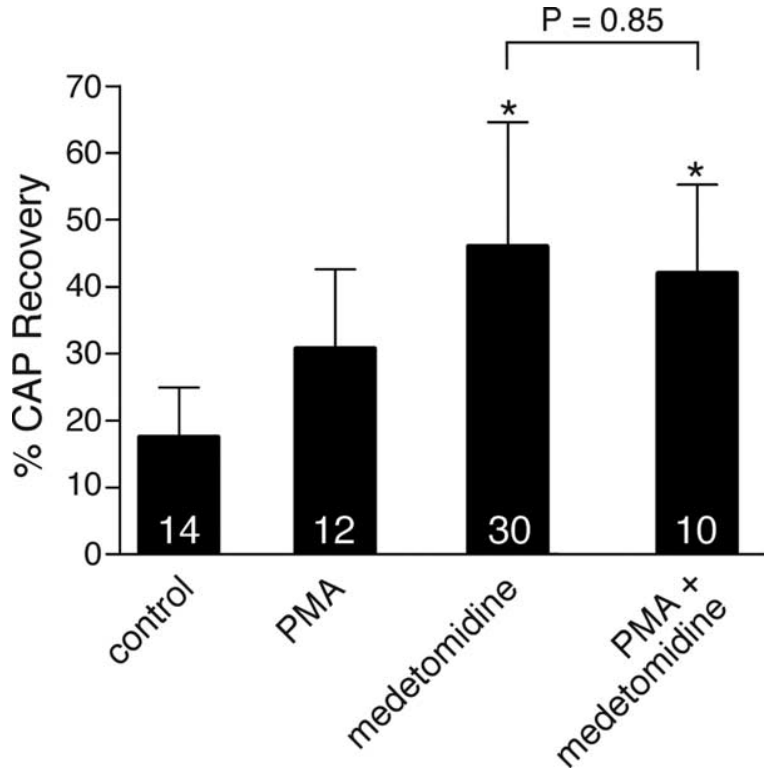

Figure 3. PKC activation with $0.1 \mu \mathrm{M}$ PMA showed a modest improvement in CAP recovery after $0 G \mathrm{D}$, which was not additive with the $\alpha 2 \mathrm{AR}$ agonist medetomodine, suggesting a common pathway. Numbers within the bars represent the number of nerves used for each treatment. Error bars indicate SD. ${ }^{*} p<0.002$ versus control.

atipamezole was tested on dorsal columns of spinal cord. The recordings were performed under the same conditions as for optic nerve and also revealed a protective effect (control: $52 \pm 10 \%$ vs $76 \pm 23 \%$ with atipamezole, $p=0.043$; data not shown). This suggests that $\alpha 2 \mathrm{AR}$-dependent injury mechanisms triggered by OGD may be common to many white matter tracts.

Agonist-dependent PKC-mediated desensitization of $\alpha 2 \mathrm{AR}$ The similar protective effects of either $\alpha 2 \mathrm{AR}$ agonists and antagonists was curious and unexpected. One explanation may involve receptor desensitization in response to persistent activation by agonists, so that with either treatment, the net effect was a reduction of $\alpha 2 \mathrm{AR}$ activity. One pathway by which agonist activation results in a desensitization of $\alpha 2 \mathrm{AR}$ signaling involves receptor phosphorylation by protein kinase C (PKC) (Liang et al., 1998). This phosphorylation may represent a mechanism by which crosstalk between different subtypes of adrenergic receptors, or between adrenergic receptors and other G-protein-coupled receptors, can occur (Liang et al., 1998, 2002). We investigated the possibility that in white matter injured by OGD, persistent stimulation of $\alpha 2 \mathrm{AR}$ leads to an ultimate decrease of its function through PKC activation. As shown in Figure 3, PKC activation with phorbol-12-myristate-13-acetate modestly increased recovery to $32 \pm 10 \%$, which did not reach statistical significance $(p=$ $0.09 ; n=12$ ). More importantly, however, addition of this PKC activator to the $\alpha 2 \mathrm{AR}$ agonist medetomidine did not produce additive protective effects, suggesting a convergent pathway.

\section{Modulation of axonal $\mathrm{Ca}^{2+}$ by the $\alpha 2 \mathrm{AR}$-signaling pathway}

The central event in the pathophysiology of white matter injury during ischemia is the excess influx of $\mathrm{Ca}^{2+}$ ions in the cytosol (Stys, 2004), which leads to irreversible cellular injury. It is therefore logical to hypothesize that the substantial protective effect of $\alpha 2 \mathrm{AR}$ manipulation would affect axonal $\mathrm{Ca}^{2+}$ accumulation. To visualize axonal $\mathrm{Ca}^{2+}$ change during in vitro OGD in axons, RONs were loaded with the low affinity $\mathrm{Ca}^{2+}$ indicator Fluo- 4 dextran $\left(K_{\mathrm{d}} \approx 2.6 \mu \mathrm{M}\right)$ and Alexa Fluor 594 dextran for visualization of axonal profiles. Images 


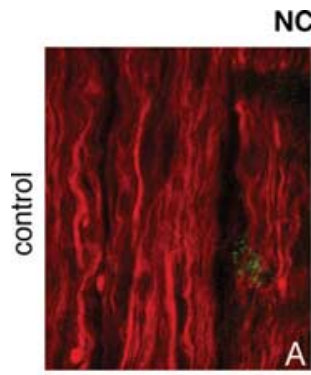

CSF
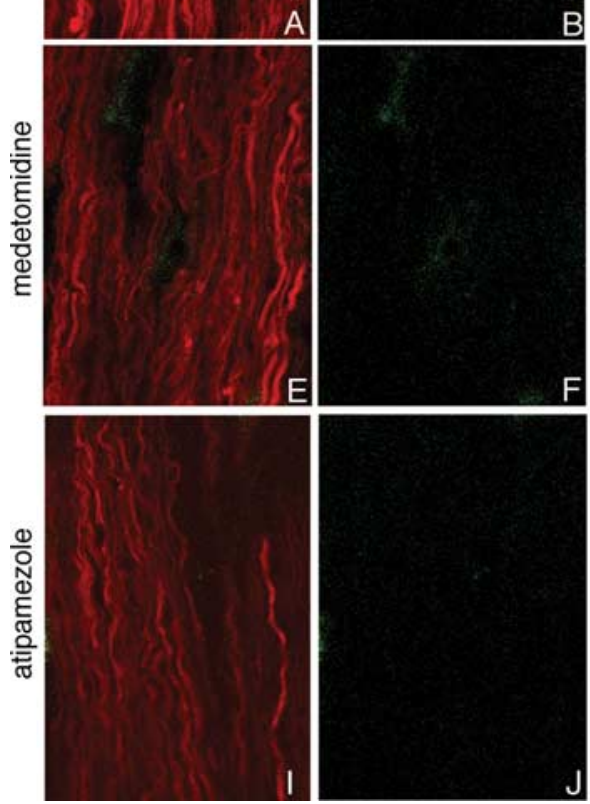

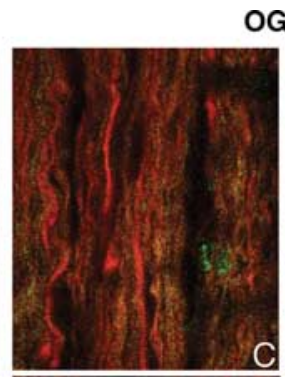

GD
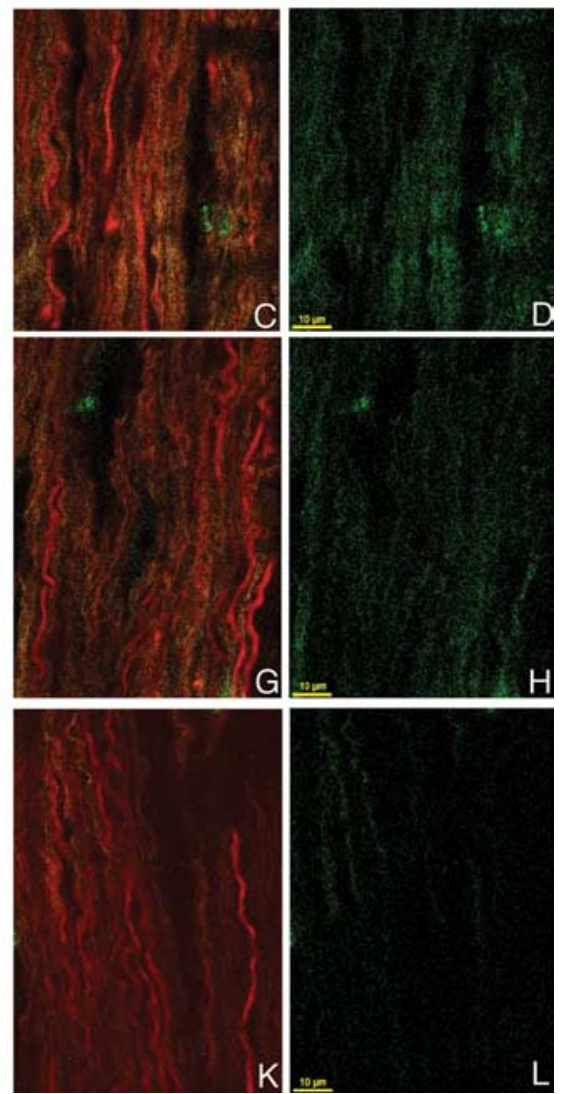

Figure 4. Confocal images of live rat optic nerve axons coloaded with Alexa Fluor 594 dextran (red) and Ca indicator Fluo-4 dextran (green) in vitro during perfusion in normal CSF (left panels without OGD: $\boldsymbol{A}, \boldsymbol{E}, \boldsymbol{I}$, both channels; $\boldsymbol{B}, \boldsymbol{F}, \boldsymbol{J}, \mathrm{Ca}^{2+}$-sensitive fluorescence) and after 30 min of exposure to $0 G D$ (right panels: $\boldsymbol{C}, \boldsymbol{G}, \boldsymbol{K}$, both channels; $\boldsymbol{D}, \boldsymbol{H}, \boldsymbol{L}$, Ca-sensitive fluorescence). Pretreatment with medetomidine $(\boldsymbol{G}, \boldsymbol{H})$ or atipamezole $(\boldsymbol{K}, \boldsymbol{L})$ reduced $0 \mathrm{GD}$-induced axonal $\mathrm{Ca}^{2+}$ accumulation.

in the left panels of Figure 4 were taken during perfusion in normal aCSF (NCSF) and demonstrate the low basal level of Fluo-4 fluorescence in healthy resting axons (Fig. $4 B, F, J$ ); images in the right panels (OGD) were taken after 30 min of OGD exposure (zero-glucose $+2 \mathrm{mM} \mathrm{NaN}_{3}$ ) and show an increase in green $\mathrm{Ca}^{2+}$-sensitive fluorescence (Fig. 4D). Preapplication of medetomidine or atipamezole reduced ischemia-induced fluorescence increase of Fluo- 4 in axons, indicating that axonal $\mathrm{Ca}^{2+}$ rise during OGD is modulated by the $\alpha 2$ AR-signaling pathway.

To assess the extent and time course of axonal $\mathrm{Ca}^{2+}$ changes during in vitro OGD more quantitatively, images of nerves loaded with fluorescent indicators were taken at 2-min intervals during perfusion in normal aCSF and then during OGD. The fluorescence changes were normalized to the average basal fluorescence before the application of OGD, and the change in fluorescence $\left(F / F_{0}\right)$ was plotted against time. As shown in Figure $5 A$, there was a substantial rise in $\mathrm{Ca}^{2+}$-dependent fluorescence during OGD, increasing $\approx 7$-fold over control levels after $30 \mathrm{~min}$. Nisoxetine, medetomidine, atipamezole and desipramine all significantly reduced Fluo-4 fluorescence rise by $\approx 23,44,69$, and $76 \%$, respectively $(p<$ $10^{-8}$ for all treatments) (Fig. $5 B$ ), indicating that the protective effects of noradrenergic modulators listed above are due in large part to reductions of ischemic $\mathrm{Ca}^{2+}$ overload in axons.

\section{$\mathrm{Na}^{+}$imaging}

Because axonal $\mathrm{Ca}^{2+}$ overload is coupled to accumulation of axoplasmic $\mathrm{Na}^{+}$(Stys and LoPachin, 1998; Nikolaeva et al.,
2005), we then examined the question whether the robust decrease in axonal $\mathrm{Ca}^{2+}$ accumulation by noradrenergic modulators was secondarily due to reduction of ischemic $\mathrm{Na}^{+}$influx. Axons were loaded with the $\mathrm{Na}^{+}$-sensitive dye CoroNa Green along with dextranconjugated Alexa Fluor 594. Under normoxic control conditions, unlike the dextran-conjugated Alexa Fluor 594 whose emission dropped by only $\approx 5 \%$, CoroNa Green emission decreased by $\approx 65 \%$ over 45 min likely because of its much lower molecular weight (it is not available as a dextran conjugate) and therefore more rapid efflux from axons (Fig. 6A). Therefore, CoroNa Green fluorescence data were always compared with time-matched normoxic controls, whose fluorescence decay was consistent enough to allow such comparisons (Nikolaeva et al., 2005); of note, percentage changes $<100 \%$ do not necessarily imply a decrease in axonal $\mathrm{Na}^{+}$. As expected, OGD induced a significant axonal $\mathrm{Na}^{+}$increase after 30 min compared with time-matched normoxic controls (CoroNa Green fluorescence at $t=30 \mathrm{~min}$ of OGD vs $t=0$ min: $94 \pm 14 \%, n=46$ axons, compared with $56 \pm 22 \%, n=86$, during normoxia, $\mathrm{P} \approx 0$ ) (Fig. $6 \mathrm{~B}$ ). Blocking voltage-gated $\mathrm{Na}^{+}$channels with tetrodotoxin (TTX) significantly reduced $(78 \pm 13 \%, p=5 \times$ $10^{-6} n=108$ vs drug-free OGD) but did not completely block the ischemic $\mathrm{Na}^{+}$accumulation, with a substantial axonal $\mathrm{Na}^{+}$ increase remaining compared with control axons $(\mathrm{P} \approx 0$ vs normoxic time-matched controls), suggesting additional important routes of axonal $\mathrm{Na}^{+}$accumulation. One additional $\mathrm{Na}^{+}$influx pathway recently identified involves AMPA receptors (Ouardouz et al., 2006); we, therefore, measured axonal $\mathrm{Na}^{+}$changes in the presence of both TTX and SYM2206, a potent noncompetitive AMPA receptor antagonist. The combination further reduced axonal $\mathrm{Na}^{+}$loading compared with TTX alone $(56 \pm 11 \%$; $n=$ 75 vs $78 \pm 13 \%, p=8 \times 10^{-12}$ ), which was identical to normoxic control fluorescence levels $(56 \pm 21 \% ; n=86, p=0.99)$. Atipamezole alone was also highly effective at reducing ischemic axonal $\mathrm{Na}^{+}$accumulation $(63 \pm 24 \%, n=116)$ to levels that were not significantly different from normoxic time-matched controls $(p=0.18)$. Together, these results confirm that the two major routes of ischemic axonal $\mathrm{Na}^{+}$influx (TTX-sensitive $\mathrm{Na}^{+}$channels and AMPA receptors) in optic nerve are similar to those recently shown in dorsal column axons (Ouardouz et al., 2006). Importantly, the present results with atipamezole further suggest that both $\mathrm{Na}^{+}$influx pathways are modulated by the noradrenergic system.

\section{$\alpha 2$ a receptors are expressed on axons and astrocytes}

Given the important role of $\alpha 2$ ARs in the genesis of ischemic white matter damage, we proceeded to examine the subcellular distribution of these receptors immunochemically. Double labeling in RONs and dorsal columns was performed using antibodies against $\alpha 2$ a, the most abundant $\alpha 2$ receptor subtype in the CNS 


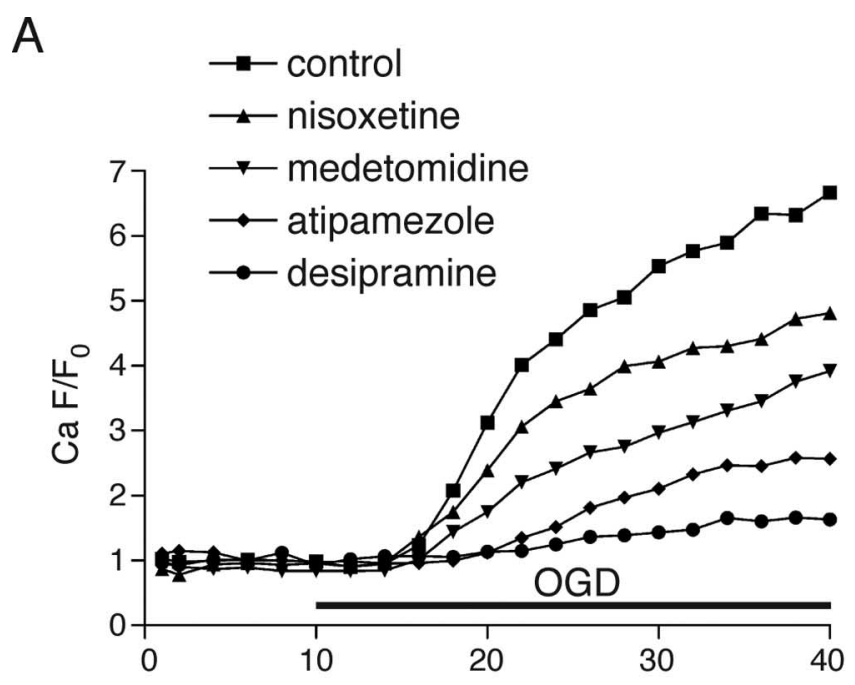

B

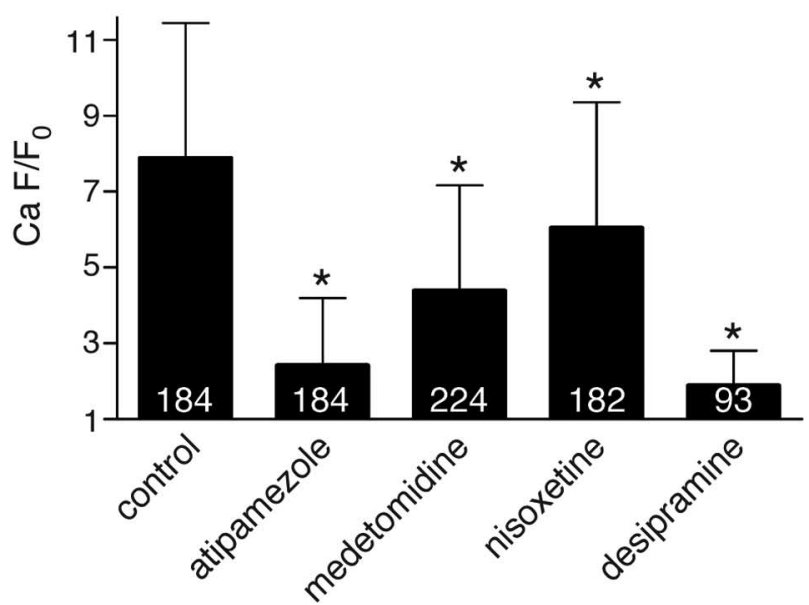

Figure 5. A, Time course of normalized axonal green $\left(\mathrm{Ca}^{2+}\right.$-dependent)/red $\left(\mathrm{Ca}^{2+}\right.$ independent) fluorescence ratio during ischemia showing $\approx 7$-fold $\mathrm{Ca}^{2+}$-sensitive fluorescence increase over baseline after $30 \mathrm{~min}$ of $\mathrm{OGD}$. Modulators of $\alpha 2$ receptors or of $\mathrm{NE}$ release significantly reduced $O G D$-induced axonal $\mathrm{Ca}^{2+}$ rise. $B$, Quantitative summary of $\mathrm{Ca}^{2+}$ responses in individual axons after $30 \mathrm{~min}$ of OGD. Numbers within the bars represent the number of individual axons analyzed for each treatment. Error bars indicate SD. ${ }^{*} p<10^{-8}$ versus control.

(Zeng and Lynch, 1991) in combination with antibodies against neurofilament and GFAP. Figure 7 shows representative sections demonstrating a predominantly punctate $\alpha 2$ a labeling pattern. Negative controls with primary antibody omitted exhibited no labeling. Positive controls were performed on sections of locus ceruleus, known to have the highest levels of $\alpha 2 \mathrm{AR}$ expression. Clear staining observed in this area (data not shown) reinforces the specificity of our labeling approach. The distribution of $\alpha 2 \mathrm{a}$ label in RON was heterogeneous: the highest receptor densities forming clusters of punctate labeling were seen between axonal bundles, in the space corresponding to glial localization (Fig. 7A). The overall distribution within the bundles of axons, identified with anti-neurofilament antibody, was much lower, with $\alpha 2 \mathrm{a}$ puncta often localizing to the outer margins of neurofilamentlabeled axon cylinders (Fig. $7 B$, arrowheads). Double labeling with GFAP revealed that some of the dense staining between axons had astroglial identity (Fig. 7C), where labeling was dense and concentrated mostly within the cell body, with less signal in the processes (Fig. 7D).
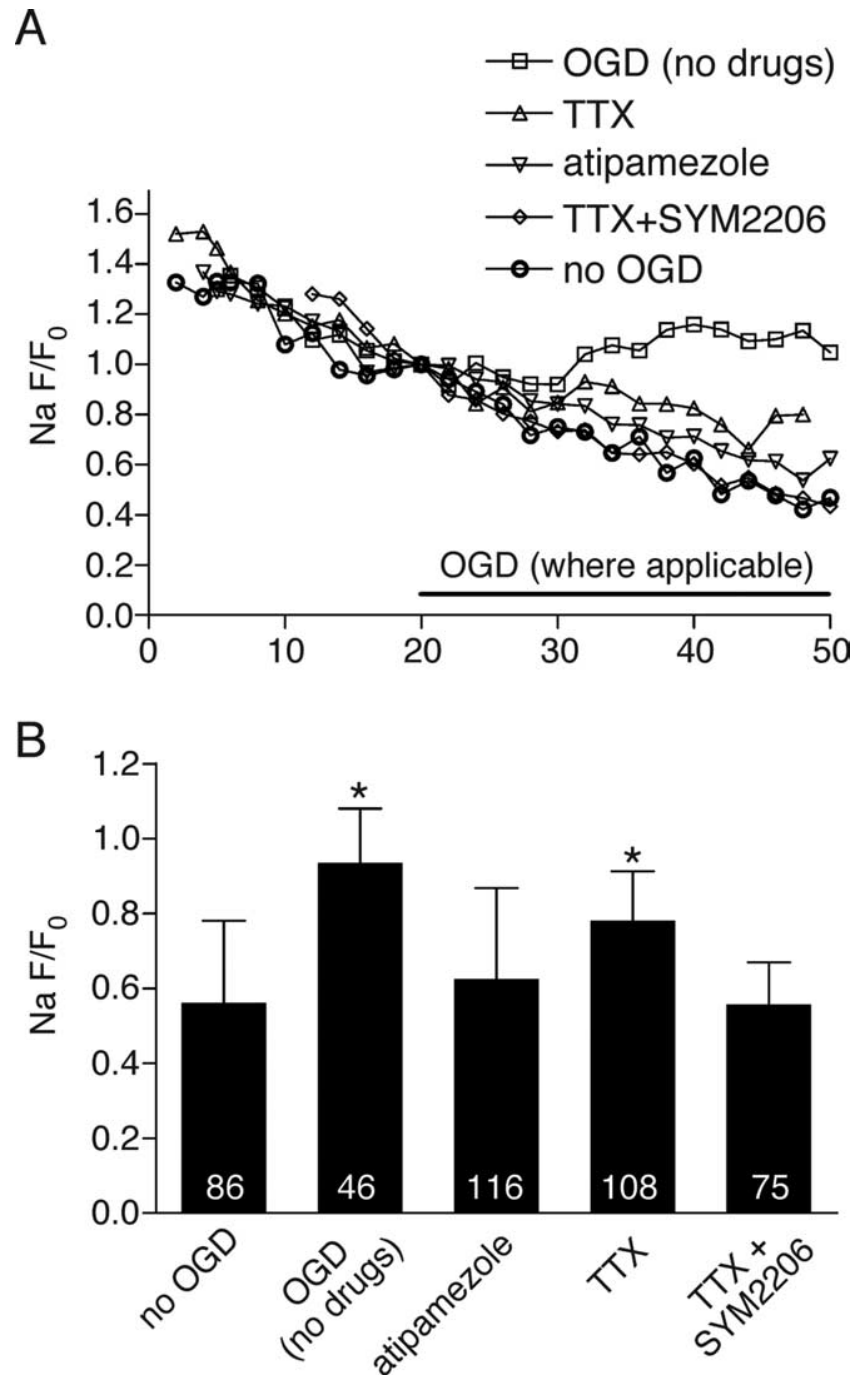

Figure 6. $\boldsymbol{A}$, Representative plots of normalized axonal $\mathrm{Na}^{+}$-dependent green (Corona Green)/red (Alexa Fluor 594 dextran) fluorescence ratios versus time. The decrease in axoplasmic fluorescence due to dye leakage in NCSF was reversed in 0 glucose/ $\mathrm{NaN}_{3}$ indicating a net axonal $\mathrm{Na}^{+}$accumulation. Blocking $\mathrm{Na}^{+}$channels with $\operatorname{TTX}(1 \mu \mathrm{M})$ reduced $\mathrm{Na}{ }^{+}$accumulation, whereas adding the AMPA receptor blocker SYM $2206(30 \mu \mathrm{M})$ in addition to TTX completely abolished detectable $\mathrm{Na}^{+}$entry. Atipamezole prevented $\mathrm{Na}^{+}$entry almost as effectively as TTX and SYM 2206 together. $\boldsymbol{B}$, Quantitative summary of $\mathrm{Na}^{+}$responses in individual axons. Numbers within the bars represent the number of individual axons analyzed for each treatment. Error bars indicate SD. * $p<10^{-5}$ versus "no OGD." There were no differences between any of the no OGD, "atipamezole" and "TTX + SYM2206" groups using multiple comparisons $(p>0.17)$.

To more precisely determine the spatial relationships between $\alpha 2 \mathrm{AR}$ and axons in an attempt to confirm localization of $\alpha 2 \mathrm{ARs}$ on the axolemma (necessary to support the hypothesis of functional axonal receptors), triple labeling for $\alpha 2 \mathrm{a} A R$, the $\alpha 3$ subunit of the $\mathrm{Na}^{+} / \mathrm{K}^{+}$ATPase [known to be homogeneously distributed on the internodal axolemma of most central myelinated axons (Young et al., 2008) thus providing a reliable marker for axon membranes] and neurofilament was performed in dorsal columns (Fig. $8 \mathrm{~A}$ ) and optic nerve (Fig. $8 \mathrm{~B}$ ). On transverse sections, punctate areas of $\alpha 2$ a labeling were often observed at the periphery of end-on axon cylinders, overlapping ring-like $\mathrm{Na}^{+} / \mathrm{K}^{+}$ATPase staining representing axolemma (Fig. 8A, $B$, arrowheads). On $Z$ projections, the $\alpha 2$ a-positive clusters were frequently seen to extend in a columnar manner for a few micrometers along the length of the axon. Discrete $\alpha 2 \mathrm{a}$-positive 


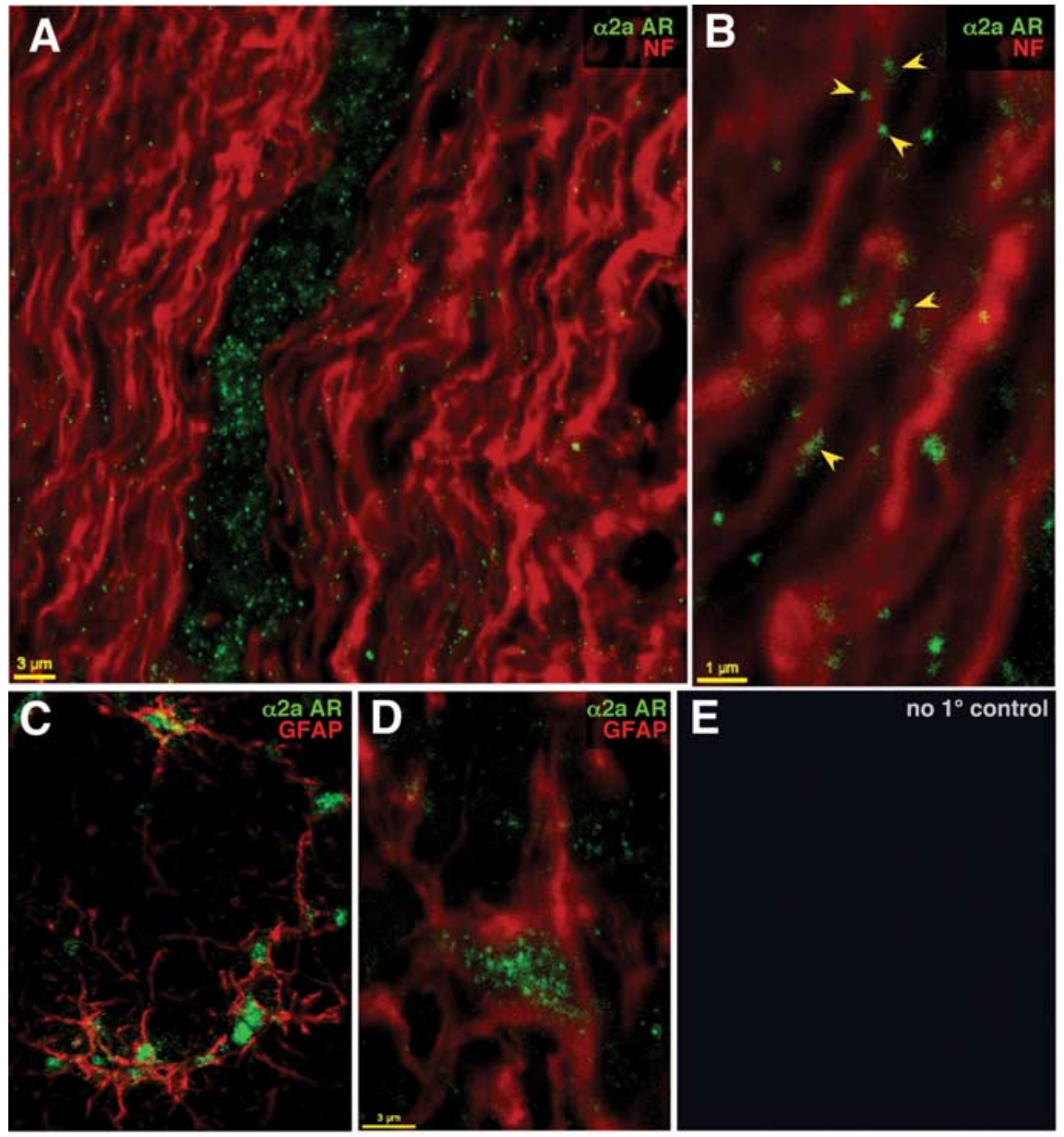

Figure 7. Optic nerve sections double labeled with $\alpha 2 \mathrm{a} A R$ (green) and neurofilament (red) antibodies $(\boldsymbol{A}, \boldsymbol{B})$, and $\alpha 2 \mathrm{a} A R$ (green) and GFAP (red) antibodies $(\boldsymbol{C}, \boldsymbol{D})$, showing punctate $\alpha 2 \mathrm{a}$ AR in association with axonal cylinders and prominent astrocyte labeling. $\boldsymbol{E}$, Controls with primary antibodies omitted showed no detectable signal.

regions were also seen outside of the $\mathrm{Na}^{+} / \mathrm{K}^{+}$ATPase rings, representing $\alpha 2 \mathrm{ARs}$ on glial structures. Given pharmacological evidence for the involvement of the norepinephrine transporters in the release of NE during OGD, immunostaining was performed to examine the distribution of this protein. Figure $8, C$ and $D$, shows ring-like labeling surrounding most axonal profiles. However, this signal mainly appeared outside the axolemma, colocalizing reliably with a marker for inner myelin loops (myelin-associated glycoprotein) (Sternberger et al., 1979), suggesting that this transporter is preferentially expressed in the myelin sheath. Glial processes also exhibited label (Fig. 8C1,3, arrowheads).

\section{Discussion}

The goal of the present study was to investigate the role of the noradrenergic system in the ischemic response of central white matter. We found that release of NE during oxygen glucose deprivation promotes functional damage to axons. Moreover, given our results with $\alpha 2$ receptor ligands affording protection against axonal injury, we conclude that OGD-mediated white matter damage is mediated at least partly by $\alpha 2$ receptors. The underlying mechanism of this protection involves a reduction in axonal $\mathrm{Na}^{+}$and $\mathrm{Ca}^{2+}$ loading. The effect could be directly axonal via $\alpha 2$ G-protein modulation of $\mathrm{Na}^{+}$channels and AMPA receptors and/or through $\alpha 2$ receptors located on astrocytes. Previous studies indicate that adrenergic receptors exert potent modula- tory actions on both TTX-sensitive $\mathrm{Na}^{+}$ channels [in particular on the persistent inward current mediated by these channels (Harvey et al., 2006)] and on AMPA receptors (Pralong and Magistretti, 1995), the two major putative $\mathrm{Na}^{+}$entry pathways in damaged myelinated axons (Stys et al., 1993; Ouardouz et al., 2006) (Fig. 6). The significant reduction in axonal $\mathrm{Ca}^{2+}$ accumulation could be secondary to a reduced $\mathrm{Na}^{+}$influx [which will in turn restrain multiple pathways responsible for axonal $\mathrm{Ca}^{2+}$ accumulation (Stys, 2004)] and/or also due to direct modulation of $\mathrm{Ca}^{2+}$ entry mechanisms [for example, voltage-gated $\mathrm{Ca}^{2+}$ channels (Lipscombe et al., 1989)]. Overall, our results are consistent with the notion that in damaged CNS axons, the adrenergic system exerts a potent modulatory effect, likely on several pathways mediating ionic dysregulation; understanding the precise mechanisms, and the potential interplay between the many varieties of adrenergic receptors, will require further study.

\section{Reducing NE release is protective}

During cerebral ischemia, significant release of NE approaching a 40-fold rise over baseline levels has been documented (Globus et al., 1989; Gustafson et al., 1991; Sumiya et al., 2001). This high extracellular NE concentration is intensely neurotoxic (Stein and Cracco, 1982; Globus et al., 1989) and may play a key role in ischemic neuronal damage (Ma et al., 2005). The mechanism of this release under ischemic conditions involves $\mathrm{Na}^{+}$-dependent reversal of the monoamine uptake carrier (Vizi, 2000; Gerevich et al., 2001; Sumiya et al., 2001). This also seems to be the case in the current study: as in the reports cited above, it is quite likely that released extracellular NE was partially responsible for the functional axonal damage in our white matter models, because lowering tissue NE content with reserpine before OGD, or decreasing carrier-mediated NE release with desipramine or nisoxetine, both significantly reduced ischemia-induced axonal $\mathrm{Ca}^{2+}$ accumulation and improved functional recovery. Note that reserpine may have other actions, such as antioxidant effects (Chakrabarti et al., 1986), contributing to our observations; however, given that reserpine actions and those of transporter inhibitors were similar, the dominant effect is likely interference with NE release.

\section{Agonist/antagonist effect on $\alpha 2$ AR-signaling pathway}

Electrophysiological recording demonstrated that in our model $\alpha 2$ ligands protected against functional axonal injury. Moreover, many reports demonstrated the protective effect of $\alpha 2 \mathrm{AR}$ agonists against neuronal death. For example, dexmedetomidine effectively decreased neuronal damage in a gerbil model of global cerebral ischemia (Kuhmonen et al., 1997) and in a rabbit focal model of ischemia (Maier et al., 1993). Clonidine, another $\alpha 2 \mathrm{AR}$ agonist, improved neuronal survival from incomplete cerebral ischemia in rats (Hoffman et al., 1991). Interestingly, other studies using models of cerebral ischemia (Gustafson et al., 1989, 

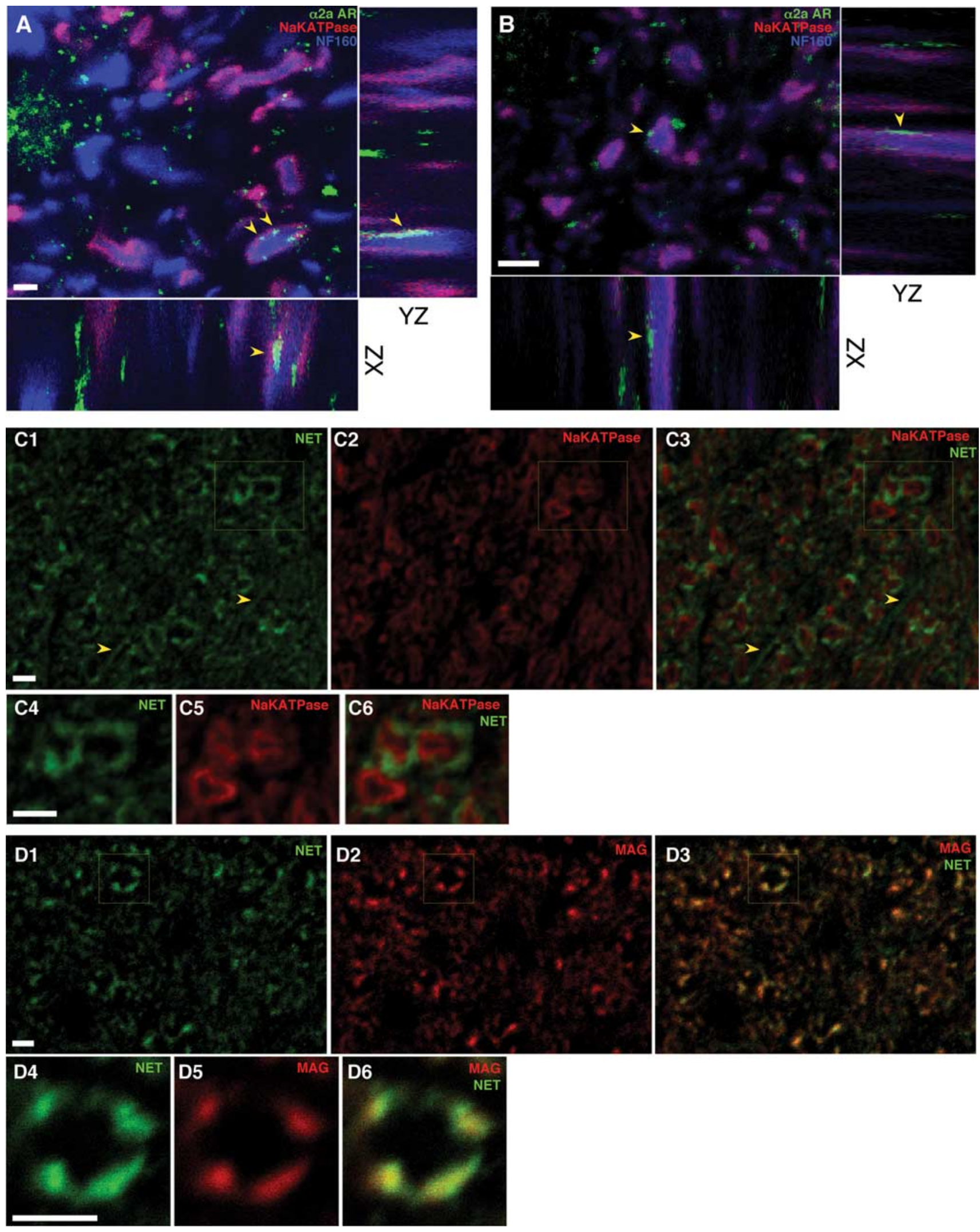

Figure 8. Dorsal columns $(\boldsymbol{A})$ and optic nerve $(\boldsymbol{B})$ sections, triple labeled with $\alpha 2$ a adrenergic receptor (green), $\alpha 3$ subunit of the $\mathrm{Na}^{+} / \mathrm{K}^{+}$ATPase (red) and neurofilament 160 (blue) antibodies, with XZ and YZ projection views of a confocal Z series acquired at $0.1 \mu \mathrm{m}$ steps. Together with the $\mathrm{Na}^{+}$and $\mathrm{Ca}^{2+}$ imaging (Figs. 5, 6), punctate $\alpha 2 a$ labeling overlapping Na ${ }^{+} / \mathrm{K}^{+} \mathrm{ATPase}^{-}$ decorated axolemma (arrowheads) provides evidence for functional axonally targeted receptors. C, Transverse sections of optic nerve labeled with NET (green) and the axolemmal marker as in $A$ and B. C4 - 6, Higher-power view of the boxed area in C1-3. D. Transverse optic nerve sections stained with NET (green) and myelin-associated glycoprotein (MAG; red), which identifies the inner surface of the myelin sheath. D4-6, Higher-power view of the boxed area in D1-3. NET is mainly expressed outside the axolemma, strongly colocalizing with inner myelin loops, indicating significant localization to the sheath. Linear profiles (arrowheads in $\mathbf{C 1}, \mathbf{3}$ ) likely represent additional NET expression on glial processes. Controls with primary antibody omitted revealed little detectable signal (data not shown). Scale bars, $2 \mu \mathrm{m}$. 
1990; Puurunen et al., 2001) have found $\alpha 2$ antagonists such as yohimbine, atipamezole and idazoxan to also be neuroprotective.

Somewhat unexpectedly, in our models of in vitro white matter injury, both agonists and antagonists were protective. We can suggest two possible explanations. One is agonist-dependent $\alpha 2 \mathrm{AR}$ desensitization, leading to reduction of receptor signaling. $\alpha 2$ receptors can couple to several different G proteins, whose $\alpha$ and $\beta \gamma$ subunits subsequently engage different effectors. The receptor's G-protein-coupling regions were demonstrated to be phosphorylation sites for PKC (Liang et al., 1998). This kinase phosphorylates Ser360 within the third intracellular loop of the $\alpha 2$ a subunit (Liang et al., 2002), leading to rapid desensitization of receptor function. Because $\alpha 2 \mathrm{AR}$ can activate PKC [via $\mathrm{G}_{\mathrm{i}^{-}}$ associated $\mathrm{G}_{\beta \gamma}$-mediated activation of phospholipase $\mathrm{C}$ (Dorn et al., 1997)], phosphorylation by PKC may also play a role in agonist-dependent desensitization. In our experiments, PKC activation with phorbol 12-myristate-13-acetate (PMA) increased axonal recovery and the effect was not additive when PMA was combined with $\alpha 2 \mathrm{AR}$ agonists, suggesting a common pathway. These results are in line with other studies demonstrating agonist-induced desensitization of $\alpha 2$ ARs (Kurose and Lefkowitz, 1994; Jewell-Motz and Liggett, 1996) and may suggest one possible explanation for the protective effect of agonists in our experiments. Another possibility is related to current evidence showing that compounds that bind to G-protein-coupled receptors can either stimulate (agonists), or reduce (inverse agonists) the receptors' basal activity, depending on the affinity of ligands for different conformational states (Kenakin, 2001). The Kenakin model suggests that if a given ligand activates the system that is quiescent (no constitutive activity) by changing a receptor into an active state, it produces excitation (agonists). However, if the system exhibits significant constitutive activity, then binding of the ligand and changing a receptor into an active state, but of less efficacy, would reduce the activity, with the net effect of the "agonist" being to reduce receptor activity (inverse agonism). Examples where $\alpha 2$-adrenoceptor agonists act as inverse agonists are well documented, e.g., clonidine, which is often considered to be a "classic" $\alpha 2$-adrenoceptor agonist tool for probing the pharmacology of this receptor, produced the same effect as several selective antagonists on the release of acetylcholine in the rat prefrontal cortex (Tellez et al., 1997). Similarly, RX 801074, a partial agonist at $\alpha 2$-adrenoreceptors, produced a competitive antagonist effect in the CNS (Chapleo et al., 1989), as did the weak partial $\alpha 2$-adrenoceptor agonist levomedetomidine in human erythroleukemia cells (Jansson et al., 1998).

\section{Action of $\alpha 2$ ligands on axonal $\mathrm{Ca}^{2+}$ and $\mathrm{Na}^{+}$content}

Various mechanisms of $\alpha 2 \mathrm{AR}$-mediated neuroprotection at nerve terminals were suggested, although the exact modes of action are not known. $\alpha 2$ ARs belong to the G-protein-coupled receptor super family: they bind to G-proteins that inhibit adenylyl cyclase, activate $\mathrm{K}^{+}$channels, and inhibit voltage-gated $\mathrm{Ca}^{2+}$ channels (Saunders and Limbird, 1999), leading to reduced intracellular $\mathrm{Ca}^{2+}$ accumulation. This in turn exhibits a powerful neuroprotective effect and also reduces further neurotransmitter release from nerve terminals. Lower levels of $\mathrm{NE}$ and glutamate release would in turn further restrain injurious events after ischemia (Bickler and Hansen, 1996; Ma et al., 2005). We found that both agonists and antagonists significantly reduced rises in axonal $\mathrm{Ca}^{2+} . \mathrm{Ca}^{2+}$ accumulation in ischemic axons is in part $\mathrm{Na}^{+}$. dependent (Nikolaeva et al., 2005), originating from intracellular and extracellular sources. We therefore hypothesized that $\alpha 2$ ligands could mediate their protective effects by restraining axonal
$\mathrm{Na}^{+}$accumulation. Indeed, blocking $\alpha 2 \mathrm{Rs}$ with the antagonist atipamezole drastically reduced ischemic $\mathrm{Na}^{+}$rise, suggesting that the $\alpha 2$-signaling pathway is coupled to a major source of $\mathrm{Na}^{+}$entry voltage-gated $\mathrm{Na}^{+}$channels. The persistent $\mathrm{Na}^{+}$ channel is one route of $\mathrm{Na}^{+}$influx during ischemia, and this persistent current was shown to be upregulated by monoamine receptors in rat spinal motoneurons (Harvey et al., 2006). Our findings are consistent with the notion that noradrenergic receptors in white matter axons can modulate persistent $\mathrm{Na}^{+}$current during ischemia, thus leading to increased $\mathrm{Na}^{+}$entry and secondarily to a greater $\mathrm{Ca}^{2+}$ accumulation and more functional damage. Interestingly, direct measurements of axonal $\left[\mathrm{Na}^{+}\right] \mathrm{re}-$ vealed that blocking $\mathrm{Na}^{+}$channels with TTX was less effective at reducing $\mathrm{Na}^{+}$influx than $\alpha 2 \mathrm{R}$ modulation (Fig. 6), suggesting that $\alpha 2$ Rs also modulate other important $\mathrm{Na}^{+}$influx pathways. Indeed, blocking AMPA receptors in addition to $\mathrm{Na}^{+}$channels with SYM2206 together with TTX abolished ischemic $\mathrm{Na}^{+}$rise completely, similar to the effects of $\alpha 2 \mathrm{R}$ modulators, suggesting that $\alpha 2 \mathrm{Rs}$ also influence AMPA receptors, directly or indirectly. This property places $\alpha 2 \mathrm{Rs}$ in an ideal position to restrain deleterious ion fluxes in ischemic axons and may represent a very attractive point for therapeutic intervention.

\section{Conclusion}

This study shows that OGD-induced release of NE plays an important role in the pathophysiology of central white matter. The $\mathrm{NE}$ release was likely due to a carrier-mediated mechanism given the beneficial role of NET inhibitors; indeed, $\alpha 2 \mathrm{AR}$ modulation itself, resulting in a profound reduction in axonal $\mathrm{Na}^{+}$accumulation, may have in turn secondarily reduced NE release. A reduction in $\mathrm{Na}^{+}$overload could be a key mechanism underlying the protective effect of $\alpha 2$ receptor ligands because it leads to a decrease in $\mathrm{Ca}^{2+}$ influx and $\mathrm{Ca}^{2+}$-related injurious events; a key consequence of reduced axonal $\mathrm{Na}^{+}$entry would be a concomitant decrease in exchanger-mediated $\mathrm{Ca}^{2+}$ entry and in carriermediated release of glutamate (Li et al., 1999) and possibly other substances. The sources of axonal $\mathrm{Na}^{+}$overload $\left(\mathrm{Na}^{+}\right.$channels and AMPA receptors) could be affected directly by $\alpha 2 \mathrm{AR}$ located on the axonal membrane. The results of this study provide new insights into the involvement of the noradrenergic system in axonal survival in central white matter and suggest exploration of noradrenergic-based therapeutic strategies.

\section{References}

Bhardwaj A, Brannan T, Martinez-Tica J, Weinberger J (1990) Ischemia in the dorsal hippocampus is associated with acute extracellular release of dopamine and norepinephrine. J Neural Transm Gen Sect 80:195-201.

Bickler PE, Hansen BM (1996) Alpha 2-adrenergic agonists reduce glutamate release and glutamate receptor-mediated calcium changes in hippocampal slices during hypoxia. Neuropharmacology 35:679-687.

Chakrabarti S, Kumar S, Shankar R (1986) Reserpine inhibition of lipid peroxidation and protein phosphorylation in rat brain. Biochem Pharmacol 35:1611-1613.

Chapleo CB, Butler RC, England DC, Myers PL, Roach AG, Smith CF, Stillings MR, Tulloch IF (1989) Heteroaromatic analogues of the alpha 2-adrenoreceptor partial agonist clonidine. J Med Chem 32:1627-1630.

Dixon WR, Mosimann WF, Weiner N (1979) The role of presynatpic feedback mechanisms in regulation of norepinephrine release by nerve stimulation. J Pharmacol Exp Ther 209:196-204.

Dorn GW 2nd, Oswald KJ, McCluskey TS, Kuhel DG, Liggett SB (1997) Alpha 2A-adrenergic receptor stimulated calcium release is transduced by Gi-associated G(beta gamma)-mediated activation of phospholipase C. Biochemistry 36:6415-6423.

Gerevich Z, Tretter L, Adam-Vizi V, Baranyi M, Kiss JP, Zelles T, Vizi ES (2001) Analysis of high intracellular $[\mathrm{Na}+]$-induced release of $[3 \mathrm{H}]$ noradrenaline in rat hippocampal slices. Neuroscience 104:761-768. 
Globus MY, Busto R, Dietrich WD, Martinez E, Valdés I, Ginsberg MD (1989) Direct evidence for acute and massive norepinephrine release in the hippocampus during transient ischemia. J Cereb Blood Flow Metab 9:892-896.

Gustafson I, Miyauchi Y, Wieloch TW (1989) Postischemic administration of idazoxan, an alpha-2 adrenergic receptor antagonist, decreases neuronal damage in the rat brain. J Cereb Blood Flow Metab 9:171-174.

Gustafson I, Westerberg E, Wieloch T (1990) Protection against ischemiainduced neuronal damage by the alpha 2-adrenoceptor antagonist idazoxan: influence of time of administration and possible mechanisms of action. J Cereb Blood Flow Metab 10:885-894.

Gustafson I, Westerberg EJ, Wieloch T (1991) Extracellular brain cortical levels of noradrenaline in ischemia: effects of desipramine and postischemic administration of idazoxan. Exp Brain Res 86:555-561.

Harvey PJ, Li X, Li Y, Bennett DJ (2006) Endogenous monoamine receptor activation is essential for enabling persistent sodium currents and repetitive firing in rat spinal motoneurons. J Neurophysiol 96:1171-1186.

Hoffman WE, Cheng MA, Thomas C, Baughman VL, Albrecht RF (1991) Clonidine decreases plasma catecholamines and improves outcome from incomplete ischemia in the rat. Anesth Analg 73:460-464.

Honmou O, Young W (1995) Norepinephrine modulates excitability of neonatal rat optic nerves through calcium-mediated mechanisms. Neuroscience 65:241-251.

Jansson CC, Kukkonen JP, Näsman J, Huifang G, Wurster S, Virtanen R, Savola JM, Cockcroft V, Akerman KE (1998) Protean agonism at alpha2A-adrenoceptors. Mol Pharmacol 53:963-968.

Jewell-Motz EA, Liggett SB (1996) G protein-coupled receptor kinase specificity for phosphorylation and desensitization of alpha2-adrenergic receptor subtypes. J Biol Chem 271:18082-18087.

Kenakin T (2001) Inverse, protean, and ligand-selective agonism: matters of receptor conformation. FASEB J 15:598-611.

Kuhmonen J, Pokorný J, Miettinen R, Haapalinna A, Jolkkonen J, Riekkinen P Sr, Sivenius J (1997) Neuroprotective effects of dexmedetomidine in the gerbil hippocampus after transient global ischemia. Anesthesiology 87:371-377.

Kurose H, Lefkowitz RJ (1994) Differential desensitization and phosphorylation of three cloned and transfected alpha 2-adrenergic receptor subtypes. J Biol Chem 269:10093-10099.

Langer SZ (1974) Presynaptic regulation of catecholamine release. Biochem Pharmacol 23:1793-1800.

Laudenbach V, Mantz J, Lagercrantz H, Desmonts JM, Evrard P, Gressens P (2002) Effects of alpha(2)-adrenoceptor agonists on perinatal excitotoxic brain injury: comparison of clonidine and dexmedetomidine. Anesthesiology 96:134-141.

Li S, Mealing GA, Morley P, Stys PK (1999) Novel injury mechanism in anoxia and trauma of spinal cord white matter: glutamate release via reverse $\mathrm{Na}+$-dependent glutamate transport. J Neurosci 19:RC16.

Liang M, Eason MG, Jewell-Motz EA, Williams MA, Theiss CT, Dorn GW 2nd, Liggett SB (1998) Phosphorylation and functional desensitization of the alpha2A-adrenergic receptor by protein kinase C. Mol Pharmacol 54:44-49.

Liang M, Eason MG, Theiss CT, Liggett SB (2002) Phosphorylation of Ser360 in the third intracellular loop of the alpha2A-adrenoceptor during protein kinase C-mediated desensitization. Eur J Pharmacol 437:41-46.

Lipscombe D, Kongsamut S, Tsien RW (1989) Alpha-adrenergic inhibition of sympathetic neurotransmitter release mediated by modulation of N-type calcium-channel gating. Nature 340:639-642.

Ma D, Rajakumaraswamy N, Maze M (2005) alpha2-Adrenoceptor agonists: shedding light on neuroprotection? Br Med Bull 71:77-92.

Maier C, Steinberg GK, Sun GH, Zhi GT, Maze M (1993) Neuroprotection by the alpha 2-adrenoreceptor agonist dexmedetomidine in a focal model of cerebral ischemia. Anesthesiology 79:306-312.

Malek SA, Coderre E, Stys PK (2003) Aberrant chloride transport contributes to anoxic/ischemic white matter injury. J Neurosci 23:3826-3836.

Mandela P, Ordway GA (2006) The norepinephrine transporter and its regulation. J Neurochem 97:310-333.

Martel J, Chopin P, Colpaert F, Marien M (1998) Neuroprotective effects of the alpha2-adrenoceptor antagonists (+)-efaroxan and (+/-)-idazoxan, against quinolinic acid-induced lesions of the rat striatum. Exp Neurol 154:595-601.
Milner TA, Lee A, Aicher SA, Rosin DL (1998) Hippocampal alpha2aadrenergic receptors are located predominantly presynaptically but are also found postsynaptically and in selective astrocytes. J Comp Neurol 395:310-327.

Nikolaeva MA, Mukherjee B, Stys PK (2005) Na+-dependent sources of intra-axonal $\mathrm{Ca}^{2+}$ release in rat optic nerve during in vitro chemical ischemia. J Neurosci 25:9960-9967.

Ouardouz M, Malek S, Coderre E, Stys PK (2006) Complex interplay between glutamate receptors and intracellular $\mathrm{Ca} 2+$ stores during ischaemia in rat spinal cord white matter. J Physiol 577:191-204.

Paris A, Mantz J, Tonner PH, Hein L, Brede M, Gressens P (2006) The effects of dexmedetomidine on perinatal excitotoxic brain injury are mediated by the alpha2A-adrenoceptor subtype. Anesth Analg 102:456-461.

Perego C, Gatti S, Vetrugno GC, Marzatico F, Algeri S (1992) Correlation between electroencephalogram isoelectric time and hippocampal norepinephrine levels, measured by microdialysis, during ischemia in rats. J Neurochem 59:1257-1262.

Pralong E, Magistretti PJ (1995) Noradrenaline increases K-conductance and reduces glutamatergic transmission in the mouse entorhinal cortex by activation of alpha 2-adrenoreceptors. Eur J Neurosci 7:2370-2378.

Puurunen K, Jolkkonen J, Sirviö J, Haapalinna A, Sivenius J (2001) An alpha(2)-adrenergic antagonist, atipamezole, facilitates behavioral recovery after focal cerebral ischemia in rats. Neuropharmacology 40:597-606.

Saunders C, Limbird LE (1999) Localization and trafficking of alpha2adrenergic receptor subtypes in cells and tissues. Pharmacol Ther 84:193-205.

Schuldiner S, Shirvan A, Linial M (1995) Vesicular neurotransmitter transporters: from bacteria to humans. Physiol Rev 75:369-392.

Stein SC, Cracco RQ (1982) Cortical injury without ischemia produced by topical monoamines. Stroke 13:74-83.

Sternberger NH, Quarles RH, Itoyama Y, Webster HD (1979) Myelinassociated glycoprotein demonstrated immunocytochemically in myelin and myelin-forming cells of developing rat. Proc Natl Acad Sci U S A 76:1510-1514.

Stys PK (2004) White matter injury mechanisms. Curr Mol Med 4:113-130. Stys PK, Lopachin RM (1998) Mechanisms of ion flux in anoxic myelinated CNS axons. Neuroscience 82:21-32.

Stys PK, Ransom BR, Waxman SG (1991) Compound action potential of nerve recorded by suction electrode: a theoretical and experimental analysis. Brain Res 546:18-32.

Stys PK, Sontheimer H, Ransom BR, Waxman SG (1993) Non-inactivating, TTX-sensitive $\mathrm{Na}^{+}$conductance in rat optic nerve axons. Proc Natl Acad Sci U S A 90:6976-6980.

Sumiya Y, Torigoe K, Gerevich Z, Köfalvi A, Vizi ES (2001) Excessive release of $[3 \mathrm{H}]$ noradrenaline by veratridine and ischemia in spinal cord. Neurochem Int 39:59-63.

Talke P, Bickler PE (1996) Effects of dexmedetomidine on hypoxia-evoked glutamate release and glutamate receptor activity in hippocampal slices. Anesthesiology 85:551-557.

Talley EM, Rosin DL, Lee A, Guyenet PG, Lynch KR (1996) Distribution of alpha 2A-adrenergic receptor-like immunoreactivity in the rat central nervous system. J Comp Neurol 372:111-134.

Tellez S, Colpaert F, Marien M (1997) Acetylcholine release in the rat prefrontal cortex in vivo: modulation by alpha 2-adrenoceptor agonists and antagonists. J Neurochem 68:778-785

Venugopalan VV, Ghali Z, Sénécal J, Reader TA, Descarries L (2006) Catecholaminergic activation of G-protein coupling in rat spinal cord: further evidence for the existence of dopamine and noradrenaline receptors in spinal grey and white matter. Brain Res 1070:90-100.

Virtanen R, Savola JM, Saano V (1989) Highly selective and specific antagonism of central and peripheral alpha 2-adrenoceptors by atipamezole. Arch Int Pharmacodyn Ther 297:190-204

Vizi ES (2000) Role of high-affinity receptors and membrane transporters in nonsynaptic communication and drug action in the central nervous system. Pharmacol Rev 52:63-89.

Young EA, Fowler CD, Kidd GJ, Chang A, Rudick R, Fisher E, Trapp BD (2008) Imaging correlates of decreased axonal $\mathrm{Na}+/ \mathrm{K}+$ ATPase in chronic multiple sclerosis lesions. Ann Neurol 63:428-435.

Zeng DW, Lynch KR (1991) Distribution of alpha 2-adrenergic receptor mRNAs in the rat CNS. Brain Res Mol Brain Res 10:219-225. 